\title{
Perceptions of trends in Seychelles artisanal trap fisheries: comparing catch monitoring, underwater visual census and fishers' knowledge
}

\author{
TIM M. DAW ${ }^{1,2 *}$,JAN ROBINSON ${ }^{3}$ AND NICHOLAS A. J. GRAHAM ${ }^{2,4}$ \\ ${ }^{1}$ School of International Development, University of East Anglia, Normich NR4 7TF, UK, ${ }^{2}$ School of Marine Science and Technology, Nemcastle \\ University, Nemcastle-upon-Tyne, NE1 7RU, UK, ${ }^{3}$ Seychelles Fishing Authority, Victoria, Seychelles, and ${ }^{4}$ ARC Centre of Excellence for Coral \\ Reef Studies, James Cook University, Tomnsville, QLD 4811, Australia
}

Date submitted: 14 August 2009; Date accepted: 5 May 2010; First published online: 22 February 2011

\section{SUMMARY}

Fisheries scientists and managers are increasingly engaging with fishers' knowledge (FK) to provide novel information and improve the legitimacy of fisheries governance. Disputes between the perceptions of fishers and scientists can generate conflicts for governance, but can also be a source of new perspectives or understandings. This paper compares artisanal trap fishers' reported current catch rates with landings data and underwater visual census (UVC). Fishers' reports of contemporary 'normal' catch per day tended to be higher than recent median landings records. However, fishers' reports of 'normal' catch per trap were not significantly different from the median CPUE calculated from landings data, and reports of 'good' and 'poor' catch rates were indicative of variability observed in landings data. FK, landings and UVC data all gave different perspectives of trends over a ten-year period. Fishers' perceptions indicated greater declines than statistical models fitted to landings data, while UVC evidence for trends varied between sites and according to the fish assemblage considered. Divergence in trend perceptions may have resulted from differences in the spatial, temporal or taxonomic focus of each dataset. Fishers may have experienced and understood behavioural changes and increased fishing power, which may have obscured declines from landings data. Various psychological factors affect memory and recall, and may have affected these memory-based estimates of trends, while different assumptions underlying the analysis of both interview data and conventional scientific data could also have led to qualitatively different trend perceptions. Differing perspectives from these three data sources illustrate both the potential for 'cognitive conflicts' between stakeholders who do not rely on the same data sources, as well as the importance of multiple information sources to understand dynamics of fisheries. Collaborative investigation of such divergence may facilitate learning and improve fisheries governance.

\footnotetext{
*Correspondence: Dr Tim Daw e-mail: t.daw@uea.ac.uk
}

Keymords: catch per unit effort, fishers' knowledge, perceptions, Seychelles, trap fisheries, trends

\section{INTRODUCTION}

Widespread interest in fishers' knowledge (FK) for fisheries science and management (Haggan et al. 2007) derives from two main perspectives. Firstly, FK is thought to contain useful information to improve the performance of fisheries management (Jentoft et al. 1998; Haggan \& Neis 2007). FK may encompass a finer spatial resolution and be more up to date than formal scientific knowledge (Rochet et al. 2008). FK often also provides a longer historical perspective than other data sources (Dulvy \& Polunin 2004; Ames 2007; Lavides et al. 2009), especially in tropical reef fisheries (Johannes 1998) and has broader scope. For example FK may include information on ecological, social, technical and economic aspects of fisheries that have historically been neglected by conventional fisheries science (Moller et al. 2004). Secondly, the process of co-management (Jentoft et al. 1998) relies on the development of institutions that facilitate knowledge exchange between stakeholders, scientists and managers to develop greater understanding and more efficient governance (Hoefnagel et al. 2006).

Fishers and scientists commonly have diverging perceptions of resources and may be suspicious of the reliability of one another's perceptions (Hall-Arber 2003; Gray et al. 2008), creating conflicts and barriers for integrating knowledge sources in multi-stakeholder arenas. Such 'cognitive conflicts' may be the main challenge in managing common pool natural resources (Adams et al. 2003), while shared understandings can support collective action to sustain resources (Ostrom et al. 1999). However, investigating discrepancies between scientific and fishers' perceptions may also provide opportunities for expansion and revision of scientific knowledge (Johannes \& Neis 2007).

Many possible explanations exist for disagreement between scientists' and fishers' perceptions. Disputes often focus on the validity of either perception and the question of which is correct. Scientists may be sceptical when fishers dispute the severity of stock declines (termed the 'you-would-saythat' issue by Daw 2008). Indeed, political conflicts or vested interests can incentivize fishers to bias their stated views either consciously or unconsciously (Harmon-Jones \& 
Harmon-Jones 2007). However, numerous examples exist in which fishers' disputes of scientific findings have been shown to be based on more than strategic self interest (Haggan \& Neis 2007).

Disputes can arise simply because they are based on observations of different parts of the fisheries system. FK has been shown to vary according to the social context of fishers (Crona \& Bodin 2006) or by the types of gear used (Gerhardinger et al. 2006). Fishers and scientists may perceive the system at different scales (Berkes 2006), or through monitoring different variables (Verweij et al 2010). Inaccuracies or biases can also affect both scientific and fishers' perceptions, due to the context in which perceptions are formed.

Human perceptions are affected by psychological recall processes (Tversky \& Kahneman 1973), existing beliefs and behaviours (Balcetis \& Dunning 2007) and frameworks of understanding (Miller 2000; Fazey et al. 2006). Perception of trends over time requires recall, and comparison of current and former conditions, while taking account of variation to distinguish long-term trends from short-term noise (van Densen 2001). The act of recalling past conditions is accomplished by a variety of cognitive heuristics (Tversky \& Kahneman 1974). For example, the 'availability heuristic' is used when estimating the frequency of an event based on the ease with which it is recalled. As such, more available memories, which may be pleasant, unusual or emotive for the individual (Matlin 2004), will appear to be more frequent and have a greater influence on the perception of past conditions. The 'shifting baseline syndrome' has also been reported to affect fishers' perceptions of deteriorating environmental conditions (Saenz-Arroyo et al. 2005; Bunce et al. 2007) and can operate at a societal level, as a result of younger generations being unaware of past abundance (termed generational amnesia), or as a result of individuals forgetting previous abundances (termed personal amnesia) (Papworth et al. 2009).

Holm (2003) characterized the process of researching and recording $\mathrm{FK}$ as the construction of a decontextualized knowledge, which he referred to as FEK*. This useful distinction between in situ $\mathrm{FK}$, and $\mathrm{FEK}^{*}$ as the product of FK research, highlights inaccuracies or biases which may exist as artefacts of the process of generating FEK* Recording FK can be affected by political or vested interests of individuals, fisheries management regimes, and methodological aspects of the research (Maurstad 2000; Davis \& Wagner 2003).

Scientific data are also subject to potential inaccuracies due to poor resolution, biases and incorrect assumptions, and fisheries science is well known to be subject to a range of uncertainties (Charles 1998), and even the political and social context in which it is generated (Finlayson 1994). Fisheriesdependent data collection can be biased by misreporting, poor sampling design and effort (over emphasis on certain landing sites or gears), and changes in gear use and targeting behaviour by fishers in response to various socioeconomic drivers (de Mutsert et al. 2008). In many fisheries, effort is not monitored, or the resolution is low, while subtle changes in efficiency are difficult to monitor. For example, fishers can introduce or improve fishing technology (such as global positioning systems or fish-finders), change the targeting of fish or increase distance travelled, and trap soak times or effort exerted during fishing (Jennings et al. 2001). Such changes are almost impossible to record and standardize (Hilborn \& Walters 1992). Interviews with fishers have the advantage of being able to investigate such changes (see for example Neis et al. 1999; Quirijns et al. 2008; Eigaard 2009). In multispecies tropical fisheries, data collection is often aggregated at high taxonomic levels and large spatial scales. Underwater visual census (UVC) offers detailed fisheries-independent data, but biases in UVC may arise from spatial extent of sampling, habitat structure and fish behaviour (Edgar et al. 2004), and the method can normally only sample a limited proportion of the available habitat.

Moving beyond the 'who-is-right' mode of understanding disputes between FK and science becomes possible with the appreciation that all types of knowledge are partial and affected by the context in which they are created (Murray et al. 2008). Disputes may provide opportunities to expand the scope of knowledge available for resource management and revise scientific understandings, which may be based on too narrow a conception of the system (Hoffmann-Riem \& Wynne 2002).

This paper examines how perceptions of resource abundance in the Seychelles artisanal trap fishery differ according to fisher interviews and two common forms of scientific fisheries data, namely UVC by scientific divers and landings surveys conducted by fieldworkers. We compare the perceptions of catch, catch-per-unit-effort (CPUE), variance in catches and abundance trends over a 10-year period.

\section{METHODS}

\section{Study sites}

Artisanal trap fisheries of the inner Seychelles islands provide a rare opportunity among tropical artisanal fisheries of a long (10+ year) time span of catch and effort data, and UVC data on fish density and biomass.

The fishery is conducted from small boats with outboard engines of 15-40 hp, and uses three types of traditional bamboo traps (kasye). Kasye peze and kasye dormi (fixed traps) are both sturdily constructed and left for a soak time of up to three days. Kasye peze are unbaited and wedged amongst corals on the shallow reef flats, while kasye dormi are set outside the reef crest in depths of up to $60 \mathrm{~m}$ and may be baited (Daw 2008). Kasye lavol (active traps) have a lighter construction, are baited, and are placed in a variety of depths for several hours. Siganids, lethrinids and scarids are the most important families caught in traps but kasye dormi also catch substantial quantities of mullids and lutjanids. Octopus, labrids, acanthurids, serranids, haemulids, balistids, muraenids and pomacanthids are also fished, while chaetodontids and scorpaenids are frequently caught but 
discarded. Kasye lavol are used to target known spawning aggregations of Siganus sutor, in which case they catch this species almost exclusively (Robinson et al. 2004).

Trap-caught fish are used for local consumption and are typically sold by fishers themselves, in 'packets', of several fish tied together. The price of packets tends to be constant, but their weight and species composition can vary according to catches.

Three areas of Seychelles were chosen for this study to correspond with existing UVC data collection sites (Jennings et al. 1995; Fig. 1). We focused our analysis on the dominant trap type and season in each area to maximize the relationship between landings and UVC data (Table 1).

\section{Data collection}

\section{Perceptions of fishers}

Individual structured interviews were conducted during September-November 2005, focused on the dominant trap type used in each area (Table 1). In each area, a list of trap fishers was compiled from landing site visits and by speaking to fishers, local residents and Seychelles Fishing Authority (SFA) staff. All fishers that could be contacted were approached for interview. Individual trap fishers were asked about their typical catch and effort on a 'good', 'poor' and 'normal' day, their perception of trends over the past ten years (or since the start of their career if less than ten years), their typical catch and effort ten years previously, and several indicators of changes in effective effort (such as length of vessel, engine power, days fished per week, maximum depth fished, maximum distance travelled from landing site to fishing ground and trap soak time) currently and ten years previously (or since the start of their career if less than ten years). These formed part of an interview which also included understandings of fish stock dynamics and opinions on fisheries management (questionnaire adapted from Walmsley et al 2005; Appendix, see supplementary material at Journals.cambridge.org/ENC). Catches were generally reported in packets, while effort was described by the number of trap hauls per day. Mean catch per unit effort (CPUE) was calculated by dividing the day's catch by the number of trap hauls. To ensure standardized data within

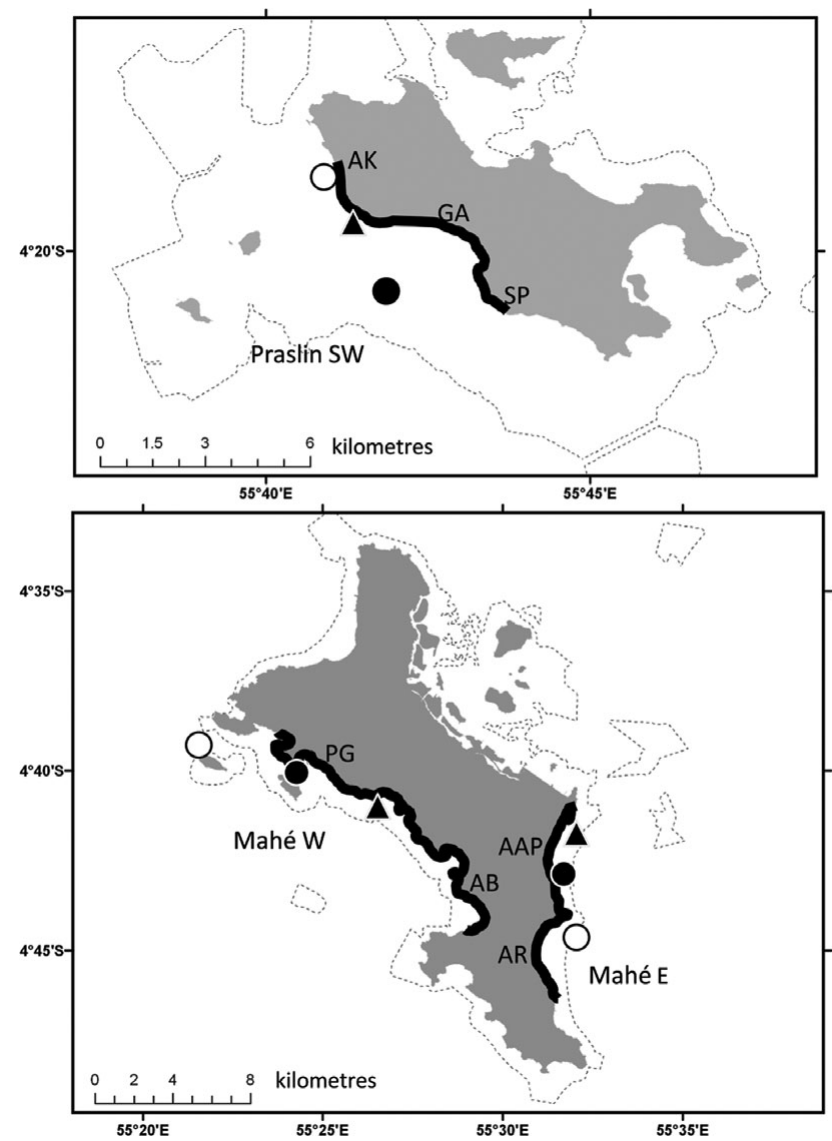

Figure 1 Seychelles study locations. Dark lines indicate the three areas of coastline where interviews were conducted. Shapes indicate underwater visual census sites in three different habitats (filled circles $=$ coral, open circles $=$ granite, triangles $=$ patch reefs $)$. Areas for the catch assessment survey are identified by abbreviations $(\mathrm{AAP}=$ Anse Aux Pins, $\mathrm{AB}=$ Anse Boileau, $\mathrm{AR}=$ Anse Royale, AK = Anse Kerlan, GA = Grande Anse, PG = Port Glaud, SP = South Praslin).

each area and maximum overlap with the UVC data, fishers were only included in the analysis if they answered questions on the dominant trap type in each region and spent all of their fishing time within the regions (Fig. 1).

Table 1 The area and trap type distinctions used to define the three fisheries selected for this study, indicating the total number of fishers identified, interviewed and who refused to be interviewed. East Mahé landings records are from June to September only. Valid area/gear refers to fishers using selected gears within the area of the UVC surveys and landings data. Valid trends refers to fishers with $\geq 8$ years of continuous gear use. Ten year trend figures from south-west Praslin include records from Grand Anse only.

\begin{tabular}{|c|c|c|c|c|c|c|c|c|}
\hline \multirow[t]{2}{*}{ Area } & \multirow[t]{2}{*}{ Gear } & \multicolumn{5}{|c|}{ Number of trap fishers } & \multicolumn{2}{|c|}{ Landings records $(n)$} \\
\hline & & Identified & Interviemed & Refusals & $\begin{array}{c}\text { Valid } \\
\text { area/gear }\end{array}$ & $\begin{array}{c}\text { Valid } \\
\text { trends }\end{array}$ & $\begin{array}{l}\text { Recent } \\
\text { catches }\end{array}$ & $\begin{array}{l}10 y r \\
\text { trend }\end{array}$ \\
\hline East Mahé & Kasye peze & 35 & 23 & 5 & 15 & 11 & 74 & 401 \\
\hline West Mahé & Kasye dormi & 10 & 8 & 0 & 7 & 5 & 150 & 312 \\
\hline $\begin{array}{l}\text { South-west } \\
\text { Praslin }\end{array}$ & Kasye lavol & 16 & 9 & 4 & 8 & 2 & 100 & 719 \\
\hline
\end{tabular}




\section{Catch assessment survey data}

Landings data were extracted from the SFA artisanal fisheries catch assessment survey (CAS), a stratified catch and effort monitoring system that has been in place since 1985 . Fieldworker effort is randomly distributed between 63 landing sites on Mahé, Praslin and La Digue, within site strata that are defined according to the number and type of boats active at the sites. Fieldworkers record fishing activities (number and types of vessels fishing, number of trips, and number and type of gears used) and landings are estimated from counts of the number of fish or packets, sample weights and estimated percentage taxonomic composition of catches (Mees 1990).

The CAS distinguishes active traps (kasye lavol) from fixed traps, but not between the two types of fixed traps (kasye peze and skayse dormi). Interviews with trap fishers indicated that kasye dormi were predominantly used in west Mahé and that there is typically a seasonal pattern in the use of fixed traps in east Mahé, with kasye dormi being used in the calmer north-west monsoon and at least 75\% of fishers exclusively using kasye peze inside the reef during the rougher south-east monsoon. Thus, to maximize the overlap between interview data on kasye peze, landings from fixed traps during the southeast monsoon (June-September) were selected. Records for fixed traps and active traps from west Mahé and southwest Praslin were taken from all months, assuming that they represented kasye dormi and kasye lavol, respectively. The few landings records from vessels without outboard engines were excluded, as all interviewees used outboard engines. Mean CPUE was calculated by dividing daily catch by the gear number. Some data $(0.5-10 \%$ depending on area) were excluded, as the number of gears had apparently been entered erroneously as one, inflating estimates of CPUE.

\section{Undermater visual census}

Fisheries-independent indications of trends in fish biomass were obtained from UVC conducted in 1994 and 2005. Three sites, representing carbonate reef, granitic reef and patch reef habitats, were surveyed within each of the three areas (Fig. 1). At each site, 16 replicate 7 -m radius point-count surveys of reef fishes were conducted. The abundance and size of 134 species of diurnally-active reef-associated fish were recorded at each count (Jennings et al. 1995; Graham et al. 2006). Length calibration was achieved by estimating the lengths of a random assortment of lengths of PVC pipe before each day's sampling, until the observer was within an error range of $1 \mathrm{~cm}$; mean errors for 1994 and 2005 were $3.1 \%$ and $2.2 \%$, respectively (Graham et al. 2007). Abundance-length data were converted to biomass using published length-weight relationships (Letourneur et al. 1998; Froese \& Pauly 2006).

\section{Data analysis}

\section{Catches as reported by fishers}

Most fishers reported catches in numbers of packets. To allow comparison with landings data, packet numbers were converted to $\mathrm{kg}$ based on a sample of 239 original SFA fieldworker datasheets detailing weights of individual packets from July to December 1996 and from July 2004 until June 2005. Packets were significantly larger in $2004(p<0.001)$. Accordingly, estimates of current and past (ten years previous) catches from fisher interviews were converted by multiplying number of packets by $3.63 \mathrm{~kg}$ and $2.94 \mathrm{~kg}$, respectively.

\section{Contemporary catch and CPUE}

For an indication of 'current' catches, a subset of landings data was taken for a three-year period prior to the interviews in order to provide enough data $(n=75-150)$, to indicate the frequency distribution and central tendency of catches in each area. To capture variability in catches, records representing the aggregate catch of more than one boat ( $c .10 \%$ of records) were removed. Frequency distributions of catch and CPUE were plotted for each area. Owing to the positively skewed nature of the landings data and the existence of outliers, median rather than mean values were chosen to compare with fishers' perceptions of a 'normal' day's catch and CPUE.

For each interviewed fisher, the difference between median landings records, and their reported normal catch and catch per trap (dCatch and dCPUE), was calculated as a proportion of median landings values:

$$
\text { Proportional catch difference }\left(\operatorname{dCatch}_{f a}\right)=\left(N C_{f a}-M_{a}\right) / M_{a}
$$

Where $N C_{f}$ is a normal day's catch in fishery $a$ according to fisher $f$, and $M_{a}$ is the median catch from landings data in fishery $a$.

For each fishery, the distribution of dCatch and dCPUE was tested for significant differences from zero (Wilcoxon signed ranks non-parametric test) to indicate whether reports of normal catches by fishers differed from median catches according to CAS data.

\section{Time trends as perceived by catch assessment survey}

For analysis of trends in landings data, records from between January 1995 and July 2005 were selected from the CAS database. Average catch per day and average catch per trap (CPUE) were analysed for trends. Visual assessment of data showed different trends between the three main landing sites in the south-west Praslin area, so only data from Grande Anse (where the majority of interviews were conducted) were included.

The presence of linear or non-linear trends in each time series was assessed by comparing generalized additive models (GAMs) fitted to each dataset using the gam function from the mgcv package in R. GAMs allow the visualization of non-linear relationships between dependent and multiple explanatory variables (Zuur et al. 2007). Seasonality in catches was accounted for by the inclusion of a month smoother term in all models except those for the east Mahé kasye peze fishery, which only included the four months of the north-east monsoon. Three alternative models were fitted to the data from each area representing (1) no trend over time (month smoother term only), (2) a linear trend over time (month 
smoother and year linear terms) and (3) a non-linear trend over time (month and year smoother terms).

The degree to which each model fitted the data was assessed using Akaike's Information Criterion (AIC). Models explaining the greatest proportion of variance with fewest parameters were indicated by the lowest AIC (Burnham \& Anderson 2002). We calculated $\triangle \mathrm{AIC}$ as the difference between each model and the best of the three models. Residual plots and graphical outputs of the GAM smoother term were examined. We did not account for autocorrelation between years, possibly leading to over estimation of the degree of fit, particularly for GAMs.

Where AIC scores indicated a linear trend with year (where the linear trend was favoured over the no-trend model, the modelled change was presented as annual change as a per cent of interpolated year 2000 values (change year ${ }^{-1} \mathrm{yr}^{2} 000^{-1}$ ). We plotted graphical representations of the year smoother from the non-linear trend and obtained an indication of recent trends by presenting the slope of the GAM between the last two years as a percentage of the ten-year mean.

\section{Time trends as perceived by undermater visual census}

Total UVC-measured fish biomass, and biomass of target species (Table S1 in Appendix, see supplementary material at Journals.cambridge.org/ENC) that were large enough ( $>6 \mathrm{~cm}$ body depth) to be caught by the inshore trap fishery (Graham et al. 2007), were analysed for differences between 1995 and 2005. Linear models with year, site (see Fig. 1) and site $\times$ year interaction were fitted for each area, to square-roottransformed data to reduce the influence of outliers. Models were selected for each area by AIC-based stepwise removal of terms (Zuur et al. 2007) and the difference between years was indicated by the significance of the year term. If site $\times$ year interactions were retained in the model selection (suggesting a different trend at each site), trends were reported for each site. Where variances were unequal between years, Welch's t-tests, which do not assume equal variance, were used to test for a difference between years. All detected differences were converted to change year ${ }^{-1} \mathrm{yr}^{2000^{-1}}$.

\section{Time trends as perceived by fishers}

Qualitative indicators of fishers' perceptions of trends were taken as the proportions of fishers who perceived a decline, no change or an increase at each site. Quantitative indicators of trends were also calculated for each fisher as the difference between reported contemporary catches and catches ten years previously (or at the start of their trap fishing activities if they had fished for less than 10 years). Only data from fishers with eight or more years of experience were used for quantitative trends. Six different quantitative trend indices were calculated as a result of using two different reports of current catches ('normal' and 'good' catches) and three different units to indicate catch, namely total daily catch, daily catch per trap in $\mathrm{kg}$ and daily catch per trap in the units used by interviewees (usually packets). Each of these trends were presented as change year ${ }^{-1} \mathrm{yr}^{2000^{-1}}$.

\section{Indicators of effective effort}

Fishers who had been fishing for at least five years were included in the analysis of indicators of effort efficiency. We calculated the proportion of interviewees who had increased, decreased or not changed with regards to each indicator and the percentage change from initial levels for each fisher. Changes for the sample were calculated in terms of mean percentage change and mean absolute change (such as miles).

\section{RESULTS}

\section{Perceptions of current catches from interviews and landings}

Landings data from all three fisheries showed a typical positively-skewed distribution of catches with extreme values at the higher end of the range (Fig. 2). The proportional difference between a fisher's normal catch and the median catch for that fishery (dCatch) was significantly greater than zero for all three fisheries (Table 2) indicating that most fishers' reports of a 'normal' catch (converted to $\mathrm{kg}$ ) were greater than the median of landings. Fishers reports tended to have greater extremes than landings; five of the 30 interviewees reported 'normal' catches that exceeded the $95 \%$ quantiles of landings data. 'Poor' catches were frequently lower than the $5 \%$ quantile of landings, and 'good' catches higher than the 95\% quantile, particularly in east Mahé. Overall, one-third of reported 'poor' catches involved nothing being caught, but only two of the 362 landings records involved no catch, both from Praslin.

When converted to CPUE, fishers' reports showed more agreement with landings data. Reports of 'normal' CPUE in east Mahe and south-west Praslin straddled the median landing (Fig. 2) and dCPUE did not differ significantly from zero (Table 2). dCPUE in west Mahé was lower than dCatch but still generally positive and differed significantly from
Table 2 Results of Wilcoxon signed rank tests (with estimated median values) of dCatch and dCPUE (differences between 'normal' catches and CPUE reported by fishers and median landings).

\begin{tabular}{|c|c|c|c|c|c|c|c|}
\hline \multirow[t]{2}{*}{ Fishery } & \multirow[t]{2}{*}{$n$} & \multicolumn{3}{|c|}{ dCatch } & \multicolumn{3}{|c|}{$d C P U E$} \\
\hline & & Median & $V$ & $p$ & Median & $V$ & $p$ \\
\hline East Mahé kasye peze & 15 & 0.998 & 115 & $<0.001$ & -0.058 & 77 & 0.352 \\
\hline West Mahé kasye dormi & 7 & 1.80 & 28 & 0.016 & 0.195 & 24 & 0.094 \\
\hline $\begin{array}{l}\text { South-west Praslin } \\
\text { kasye lavol }\end{array}$ & 8 & 0.160 & 36 & 0.001 & -0.201 & 15 & 0.742 \\
\hline
\end{tabular}


Figure 2 Frequency distributions of daily catches and catch per unit effort from three different Seychelles trap fisheries from landings data (upper panels), and individual reports of catch and CPUE from fisher interviews (lower panels, circles $=$ 'normal' day, triangles $=$ 'poor' day, squares $=$ 'good' day) lower panels show a 'strip chart' in which each fisher is represented by a different y axis value. Thick vertical lines indicate median, and dotted vertical lines indicate the $5 \%$ and $95 \%$ quantiles of landings data.
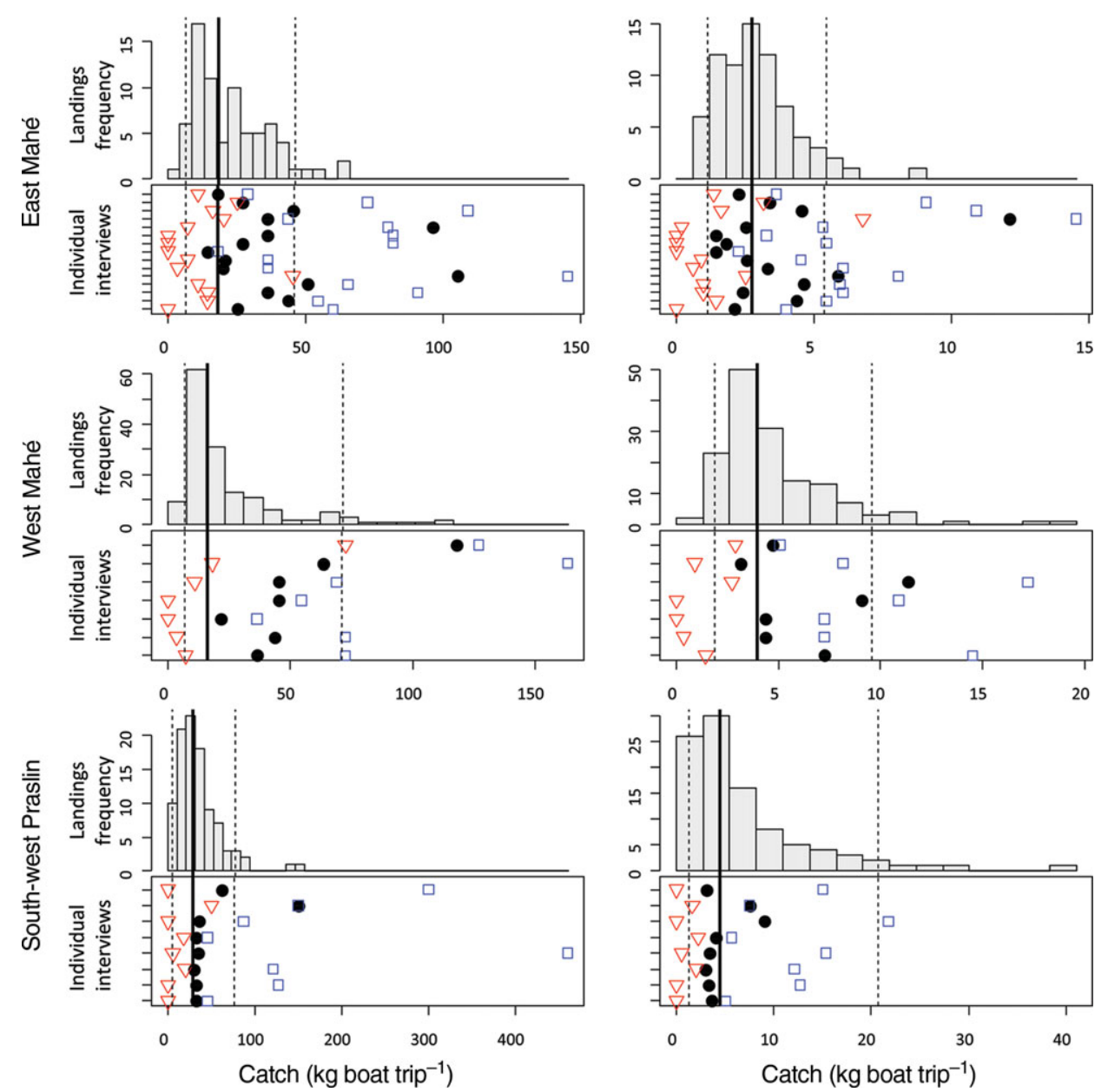

zero at $10 \%$ level. The $95 \%$ quantile of CPUE tended to be straddled by reports of 'good' CPUE (Fig. 2).

Extreme reported values were apparent in each fishery, especially for catch. Half of the 'good' catch reports in east Mahé lay outside the range of the landings data, while one 'normal' report in west Mahé was similar to maximum recorded landings. However, expressing reported data as CPUE tended to reduce the occurrence and extent of extreme values. For example, catch reports included three 'normal' and 11 'good' values that were larger than the maximum recorded landing, whereas for CPUE, only one 'normal' and two 'good' reports extended beyond maximum landings. Two reports of 'good' catches from south-west Praslin were two and three times greater than the maximum recorded landings, but were comparable to typical landings when presented as CPUE as they came from three hauls from a large number (ten) of traps.

\section{Time trends according to catch assessment survey}

Model selection indicated different trends in the three fisheries and, in the case of east Mahé, between catch and CPUE (Table 3). Highly significant year terms for west Mahé catch and CPUE and east Mahé CPUE (but not catch) were also reflected in lower AICc values for linear as compared with null models. All linear trends were positive, and equivalent to $2-15 \%$ change $\mathrm{yr}^{-1} \mathrm{yr}^{2000^{-1}}$. South-west Praslin showed no evidence of any long-term trend in CPUE, but a trend in catch was indicated by a marginally significant year term in the linear model, which was selected by AIC over the null model.

The GAMs were selected by AIC in all cases. Graphical representations of the GAM smoother terms gave an indication of the underlying trend in catches by year when seasonal trends were accounted for by the month term in the models (Table 3). All sites showed some evidence of declines over the last two years, ranging from $9 \%$ of mean values in west Mahé CPUE to 37\% in east Mahé CPUE.

\section{Time trends according to fishers' perceptions}

Most fishers $(82 \%, n=28)$ in all areas perceived that catches had declined (Table 4), but quantitative indices of trends gave different conclusions depending on which index was used (Fig. 3). Most fishers cited 'normal' catches that were less than previous catches (representing declines of up to $15 \%$ $\mathrm{yr}^{-1} \mathrm{yr}^{2000^{-1}}$ ), but roughly half of fishers' 'good' catches were greater than previous catches. In terms of the different indices, daily catch suggested less of a decline than catch per trap, and catch per trap converted to $\mathrm{kg}$ indicated less severe 
Table 3 Selection of candidate models for catch and CPUE of each fishery and indicators of trends where present. ${ }^{*}$ The lowest (i.e. best) AIC between the linear models. Smooth terms are plotted with partial residuals (shaded areas correspond to two standard errors above and below the estimate of the smooth).

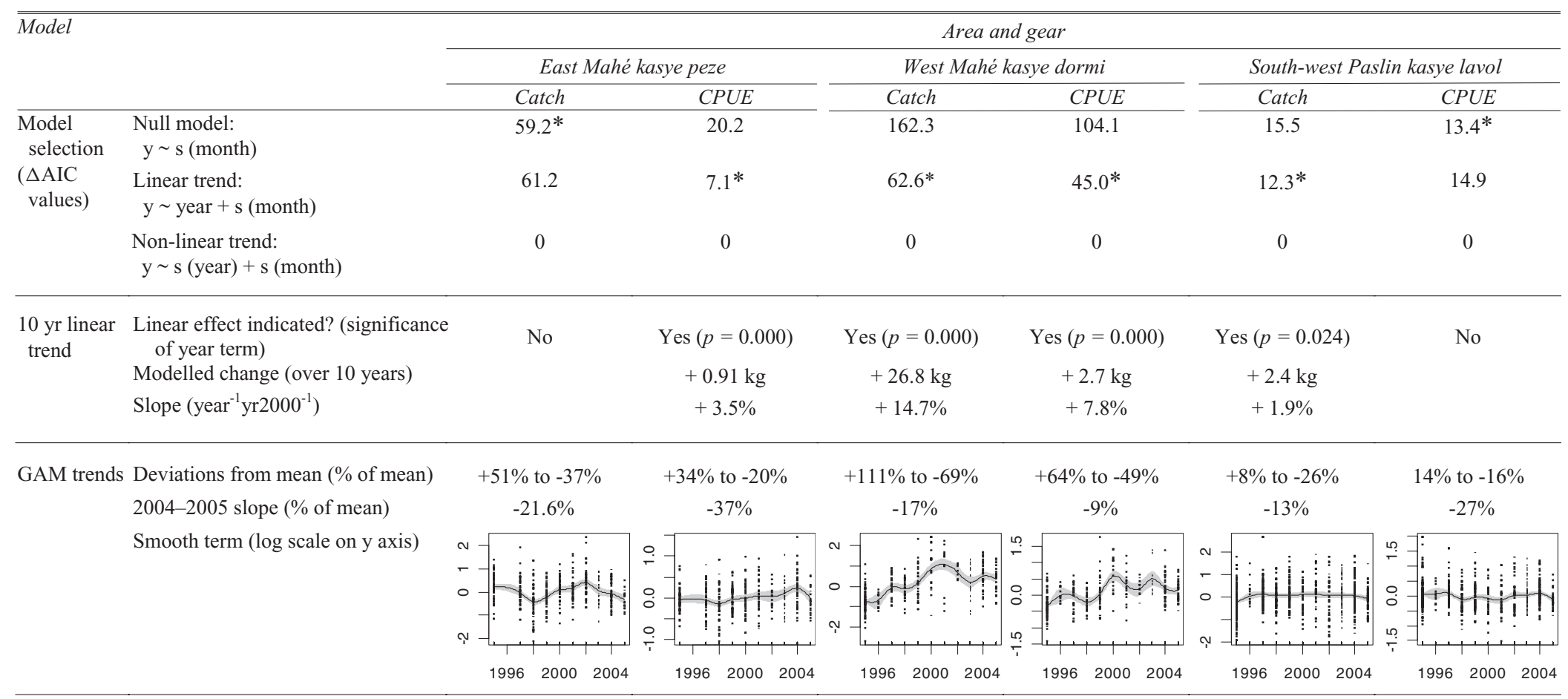


Table 4 Perceptions of trends from UVC and fisher interviews in each fishery. Proportional changes are calculated as annual change as a percentage of the modelled value for year 2000 . Shaded bars indicate responses based on 8-10 years experience, open bars indicate other time spans (nine with 3-7 years and one with 30 years due to leaving and returning to fishing).

$$
\text { Perceptionsof trends }
$$
Area and gear

\begin{tabular}{|c|c|c|c|}
\hline \multirow[b]{2}{*}{ UVC } & \multirow[b]{2}{*}{ Fishes included } & \multicolumn{2}{|c|}{ East Mahé kasye peze } \\
\hline & & All fish & Trap fish \\
\hline & Trend detected $\left(\mathrm{yr}^{-1} \mathrm{yr} 2000^{-1}\right)$ & $-1.6 \%$ & No trend \\
\hline $\begin{array}{l}\text { Fishers' } \\
\text { perceptions }\end{array}$ & Perceived trends & 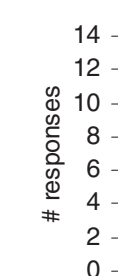 & \\
\hline
\end{tabular}

Quantitative estimates ( $n$

Change from previous to 'normal' CPUE ( $\mathrm{yr}^{-1} \mathrm{yr}^{2000^{-1}}$ ) Change from previous to 'good' catch $\left(\mathrm{yr}^{-1}-\mathrm{yr} 2000^{-1}\right)$

$$
9
$$

$-6.1 \%(\mathrm{SD}=6.7 \%)$

$-0.3 \%(\mathrm{SD}=9.5 \%)$

West Mahé kasye dormi

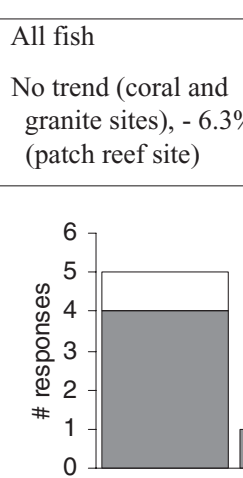

Less

No

Trap

Trap fish reef site)

reef site)

$-1.6 \%$ overall 
Figure 3 Quantitative indicators of changes in catch from trap fisher interviews in three trap fisheries, calculated by comparing past catches with either 'normal' (left panel) or 'good' (right panel) reported catches; and calculated in three different catch units (daily catch converted to $\mathrm{kg}$, CPUE converted to $\mathrm{kg} \mathrm{trap}^{-1}$ and CPUE in original reported units trap $\left.^{-1}\right)$. Asterisks indicate mean values. Vertical lines indicate zero change. Circles $=$ east Mahé kasye peze, triangles $=$ west Mahé kasye dormi, crosses $=$ south-west Praslin kasye lavol.

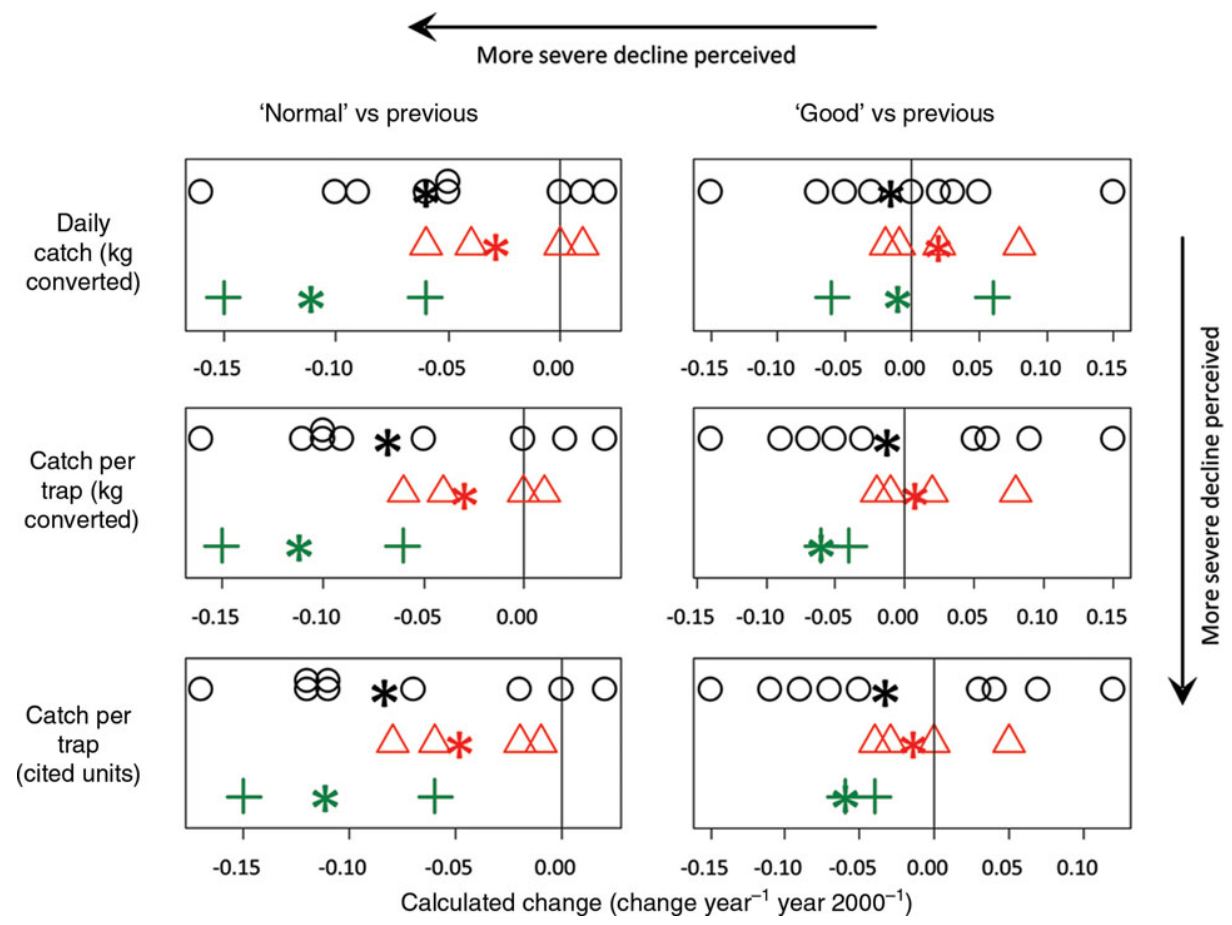

declines than catch per trap in the fishers' own units, owing to the different packet conversion for current and former times. 'Good' versus previous catch in $\mathrm{kg}$ (Fig. 3, top right), indicated no decline on average, while 'normal' versus former catch per trap in the fishers' own units (Fig. 3, lower left) suggested the most pessimistic picture, in which only 1 fisher (from east Mahé) perceived an increase in catches and 13 perceived a decrease of up to $17 \% \mathrm{yr}^{-1} \mathrm{yr} 2000^{-1}$.

\section{Time trends according to UVC data}

UVC data from 1994 and 2005 for east Mahé indicated declines in total fish biomass but not in biomass of trap fish (Welch $\mathrm{t}=2.05, p=0.04$; Table 4). There was a significant site $\times$ year interaction at west Mahé, so the three sites were tested separately. Total biomass was significantly less in 2005 at the patch reef site (Welch $\mathrm{t}=4.87, p<0.001)$, but not at the other sites, while trap fish biomass was significantly lower at all sites $(\mathrm{F}=4.98, p=0.028)$, and much lower in 2005 at the patch reef site (Welch $\mathrm{t}=3.60, p=0.001)$. No significant trends were detected in south-west Praslin.

\section{Comparisons of trend perceptions in the datasets}

Qualitatively, 10-year trend indications from the three sources of information were very different. Fisher interviews indicated declines in all areas, UVC from some sites indicated declines and landings data showed increases over the ten years. Landings did, however, indicate a decline in catches over the final one to three years of the time series. When comparing between areas, west Mahé landings data showed the strongest evidence for an increase, the least severe decline according to fisher interviews, but the most evidence for a decline according to UVC. Meanwhile, south-west Praslin showed no evidence for a decline according to UVC, but had the most pessimistic quantitative indications from fishers.

\section{Trends in fishing behaviour}

For most behavioural indicators, the majority of fishers did not report changes, but more fishers reported increases in effort than decreases (Fig. 4). The only exception was 'days fished per week' which had decreased for $14 \%(n=29)$ of fishers and increased for only $3 \%$. Vessel fishing power had commonly increased, with $45 \%(n=22)$ of fishers having upgraded to larger engines (nine fishers), or obtained engines for the first time (two fishers), and $41 \%$ of fishers fishing in larger vessels. Thirty-one per cent and 44\% $(n=16)$ of the fishers had increased the number of traps fished and soak time, respectively, with an average increase of $c .25 \%$ in each. A minority of fishers had increased the depth or distance at which they fished, with an average extension of $1.4 \mathrm{nmi}$ in their range.

\section{DISCUSSION}

In this study we compared perceptions of artisanal trap catches and CPUE, as obtained from fisher interviews and structured landings surveys, and perceptions of trends over ten years according to interviews, landings surveys and UVC. Landings data indicated lower catch per day, but similar catch per trap to fishers' stated 'poor', 'normal' and 'good' catches, both in terms of the central tendency of the data (median CPUE and 'normal' catch per trap), and the range of the data indicated by the frequency distributions and the fishers' reports of 'poor' and 'good' catches. Indications of trends over 10 years 


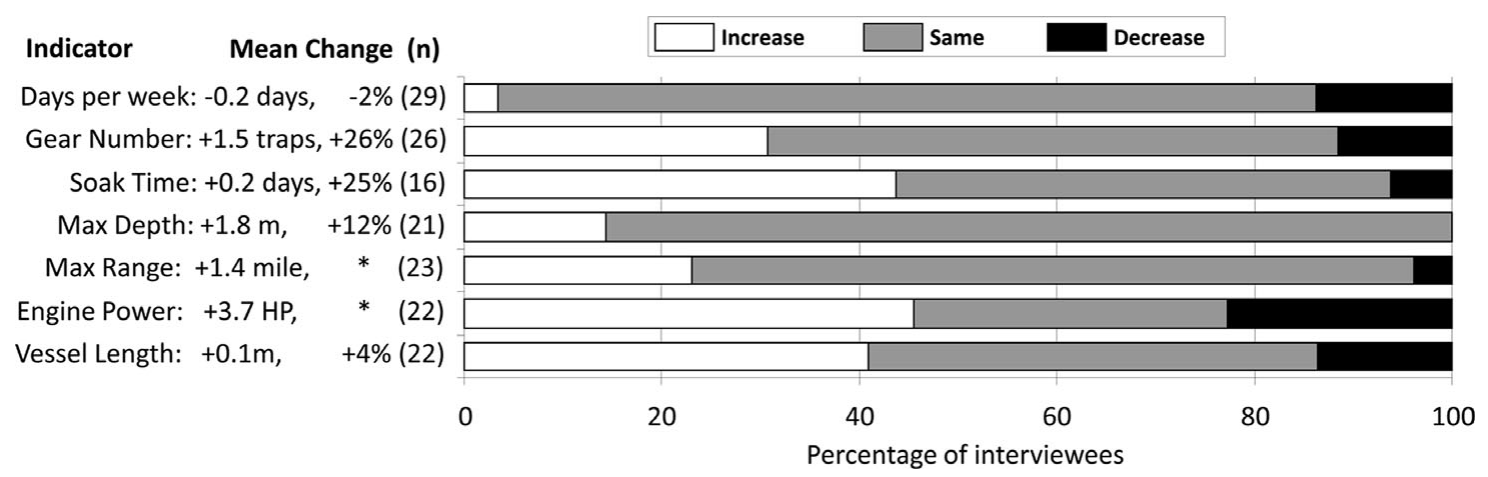

Figure 4 Changes in quantitative indicators of fishing effective effort by trap fishing interviewees during the previous 5-10 years. Mean changes are reported firstly in absolute terms and then as a percentage. Bars indicate the proportion of the interviewees whose indicators had increased, remained constant or decreased. Days per week refers to days spent fishing. Soak time refers to time between setting and lifting traps, max depth refers to depth of water in which traps were set, max range refers to the maximum distance travelled to fishing grounds. *Percentage changes in distance and engine power are not displayed owing to low or zero initial values.

however, differed widely, with fisher interviews indicating declines, landings data indicating no trends or increases, and UVC indicating no trends or a decline depending on the site and fraction of the fish community sampled.

\section{Contemporary catch indications from landings and fisher interviews}

The observed congruence between contemporary CPUE according to landings and catch per trap according to interviews is encouraging for situations in which time and resources are not available to initiate a structured landings recording programme. For Seychelles trap fisheries, it seems that if effort is carefully accounted for, a reasonable account of both the magnitude and the variability of contemporary catch per trap can be obtained from interviews with fishers (for example see Lunn \& Dearden 2006). However, similar studies over a larger range of fisheries are needed to investigate the generality of this finding.

Our findings emphasize the importance of detailed measurement of fishing effort. Catch per day gave a different and less compatible result than the more detailed catch per trap, because of variations in the quantity of traps used (2-14) and hauls made per day (1-3) by fishers. Extreme reports of high daily catches may have created suspicion of exaggeration by interviewees, but when the data were presented in terms of catch per trap, individuals' answers fell comfortably within the range of the rest of the sample.

Answers to interview questions can be affected by how interviewees interpret the context and wording of questions (Schwarz 1999). For example, a 'normal' catch may have been cited based on a range of catch experiences, which may include or exclude zero catches, or be focused on particular seasons or areas. Different cognitive heuristics may have been used to construct an answer, such as stating the first trip that is recalled from memory, calculating the desired catch to cover costs and make an acceptable profit, or attempting some form of averaging over the range of a number of recalled trips. To encourage respondents to use a similar anchoring-and-adjustment heuristic (Tversky \& Kahneman 1974), and to remove some variability owing to fishers placing more or less emphasis on particularly good catches, we asked about 'good', 'poor' and then 'normal' catches. While not eliminating problems of question interpretation, this provided a more standardized measurement of the perception of current catches, and also provided some indication of catch variability. Variability is in itself of interest, as it affects fishers' ability to perceive spatial or temporal trends in catches (Oostenbrugge et al. 2001; Pet-Soede et al. 2001; van Densen 2001), has implications for livelihoods and vulnerability, and has been shown to rise in response to increasing fishing pressure (McClanahan et al. 2008), potentially indicating loss of fish stock resilience (Hsieh et al. 2006). More generally, variance indicators have been proposed as predictors of ecological regime-shifts (Carpenter \& Brock 2006).

\section{Perception of trends from UVC and fisher interviews}

Trends perceived from fishers' and UVC data were not in accord, which can be attributed to many factors affecting the two data sources, and the limited overlap between UVC and the fishery in terms of depths, habitats and species. Kasye peze fishers tend to fish shallower than the reef slopes targeted by UVC, while kasye dormi fishers can expand beyond the shallow fringing reefs targeted by UVC onto the expansive Mahé plateau. Graham et al. (2007) estimated that only 50$60 \%$ of trap fishing grounds overlapped with habitats and depths sampled by these UVC data.

Filtering of the UVC data for 'trap fish' changed indications from 'decline' to 'no detectable decline' in east Mahé, and vice versa in west Mahé. Trends in west Mahé were different at the different sites, with severe declines indicated on the patch reef habitat. This illustrates the complexity of comparing independent indicators of fish biomass over a 
complex heterogeneous seascape and the potentially critical impact of choices of how to select and interpret scientific data for the trends perceived in a resource. If the patch-reef site was assumed to be representative of areas targeted by trap fishers, the perceptions of declines reported by fishers would be expected.

\section{Perception of trends from landings data and fisher interviews}

The importance of effort is again highlighted by different trends indicated by catch and CPUE from landings (Table 3). There was an increase in some individuals' effective effort through increasing vessel power and soak times (Fig. 4). This may account for discrepancy between landings and fishers' perceptions. Fishers may have perceived resource declines, while compensating for them by increasing effective effort. Such declines cannot be perceived from landings without detailed information on changes in fishing behaviour/technology and the spatial distribution of effort. Effective effort can also be reduced by a range of factors, including management regulations, fuel prices or, at a personal level, due to ageing, or deterioration of gear or vessels.

Although several fishers reported poor catches of zero, CAS data had few zero catches. This may be because fishers with zero catches returned directly to mooring/anchorage sites instead of the monitored landing sites, fishers avoided interviews with fieldworkers on zero-catch days, or fieldworkers preferentially sampled and interviewed fishers with landings over those without. For fisheries in which zero catches are common, the failure to record them may introduce biases in mean or raised estimates from landings data.

Few studies of the implications of cognitive processes of memory and recall currently exist in FK literature, but such processes may affect perceptions of resource trends. For example, the time window of ten years may have contributed to the differing perceptions of CPUE trends obtained from fisher interviews and CAS data. All six of the GAM smoother terms showed a decline in recent years (although caution should be taken with the interpretation of the ends of GAM smoothers; A. Zurr, personal communication 2006). Fishers answering questions about a ten-year time trend may have based their answer on recent trends that were easier to recall, even if they were questioned about trends over 10 years.

As with the majority of artisanal fisheries in the world (Berkes et al. 2001), catches from the Seychelles trap fishery are sold for profit. Changes in the gross revenue or profits from fishing may therefore be of greater importance to the fisher, and thus better remembered, than changes in quantity of catch (Matlin 2004). Increasing costs and/or decreasing fish prices could result in perceptions of a decline as profitability fell. In Seychelles, fishers' profitability may have been negatively affected by macroeconomic difficulties that worsened over the study period, making imported equipment increasingly expensive, or by decreasing unit fish prices (as indicated by the increasing trend in packet size identified over the ten years). More generally, fluctuations in fuel prices, global market prices and government subsidies for fishers may affect perceptions of trends in resource abundance.

The availability heuristic (Tversky \& Kahneman 1974) predicts that particularly large or unusual catches would dominate the perception of former catches. We compared 'normal' catches against reported former catches (assuming them also to be normal; Fig. 3, left). If these reported former catches do, in fact, refer to memorably good catches, then fishers would perceive more severe declines creating a 'memory illusion', in which declining trends are exaggerated or incorrectly perceived (Papworth et al. 2009). Memory illusion operates in the opposite direction to the 'shifting-baseline syndrome', in which severity of declines is underestimated (Saenz-Arroyo et al. 2005; Bunce et al. 2007). Such potential biases arising from recall remain a challenge for the use of memory-based perceptions of trends, in the absence of records or repeated surveys. Biases are expected to increase with the length of time over which interviewees are asked to remember. Further research is required to investigate the magnitude and impact of these biases on trend perception. Cognitive science can be used to understand the processes, but to specifically understand them in fisheries, empirical research is needed to compare memory-based verbal reports of catches with independent records of the same individual's actual catches, in different contexts.

In conducting FK research and creating FEK*, FK is filtered and adjusted through the decisions, methods and assumptions of the researchers, which may have significant impacts (for example see Fig. 3). Assuming that reports of former catches were representative of memorably 'good' catches, and thus comparing them with contemporary 'good' catches (Fig. 3, right), would imply lesser declines. Different inferences may also be generated by the method used to process catch estimates from fishers . In this study, we found trends obtained from figures converted to $\mathrm{kg}$ were apparently more negative than trends calculated using fishers' own units, and CPUE trends were more negative than catch trends (Fig. 3) owing to increasing trap numbers, thus demonstrating the critical impact that the method selected for FK processing and analysis can have on deriving conclusions. Changes in the assumptions made during the interpretation of fishers' reports, may qualitatively alter the nature of the perceived trend (O'Donnell et al. 2010).

Conflicts between scientific, or bureaucratic, perspectives on resources and those of resource users are common in fisheries (Gray et al. 2008). In this case, fishers had more pessimistic perceptions of catch trends than scientific data, but, in spite of this, fishers were not supportive of introducing effort or catch controls, or limiting entry to the fishery (Daw 2008). Thus, it is important to note that perceptions and knowledge are not the sole factors determining personal environmental behaviour (Kollmuss \& Agyeman 2002), and preferences for potential management measures are complicated by a range of political factors, values, personal interests and power relations. 


\section{CONCLUSIONS}

All three data sources gave different perceptions of trends in the biomass of fish and catches over the study period. Fishers' experience of the fishery may have resulted in more pessimistic perceptions because of (1) increasing numbers of traps and other increases in effective effort, (2) an emphasis on recent catch declines, (3) psychological biases in the recall of past catches or (4) the increasing weight of fish packets effectively reducing the price of fish. Meanwhile, landings data may have perceived positive trends as a consequence of (1) monitoring of catch by $\mathrm{kg}$ rather than packets, (2) a long 10-year perspective, without emphasis on recent trends, (3) failure to record zero catches and (4) an inability to account for increasing efficiency. In addition, the trends implied by each dataset can be qualitatively affected by changing underlying assumptions about the types of fish measured by UVC or the meaning of fishers' reports of previous catches. This illustrates how inferences can be critically impacted by the choice of methods and assumptions used to analyse either FK or scientific data. We have documented changes in effective effort, different trends identified over different timescales, habitats or species, changes in fish price and the existence of zero catches. Cognitive processes affecting trend perception are potentially highly significant, but were not measured or documented in this study and require further research.

An increasingly prevalent perspective suggests the importance of combining multiple information sources for monitoring and learning about social-ecological systems like fisheries (Folke et al. 2003). Fishers may be able to perceive trends rapidly and at small scales, which, owing to subtle increases in fishing effort or efficiency, or aggregation over large scales, are not detectable by landings data (Neis et al. 1999; Rochet et al. 2008). Meanwhile, landings data may better detect large-scale trends from background variability by integrating the catches of many different fishers (van Densen 2001). UVC may be able to monitor actual changes in biomass of fish regardless of variability and change in catchability and fisher behaviour, but may have poor coverage or limited temporal, spatial, depth or taxonomic overlap with exploited fish populations. Neither scientific nor fishers' perceptions can be considered to provide the 'true' picture of the resource. Each is partial in terms of spatial or taxonomic coverage, or the variables considered, and contextually contingent in terms of the methodology and the socioeconomic environment in which they are created. Consideration of various perceptions increases the awareness of the contingent nature of each, enables conflicts to be identified and addressed, and helps to avoid overconfidence in one signal.

Overconfidence in signals from trawler CPUE contributed to the overfishing and collapse of the northern cod fishery (Finlayson 1994; Neis 1997). Further research should involve fishers and scientists in examining the reasons why perceptions are divergent, in order to improve understandings of trends in the fishery and to investigate issues such as how changes in effective effort influence the different perspectives. Stock assessments supported by various types of fishers' knowledge are needed to provide a reliable and accepted status of the resource. Such processes also help to address 'cognitive conflicts' and facilitate social learning, which is thought to be important for co-management (Armitage et al. 2009).

In the case of the Seychelles artisanal trap fishery, new initiatives have recently been instigated to establish fisher organizations and co-management, which may provide a medium for such collaborative learning. Our research suggests that participatory research and monitoring to address diverging perceptions and understandings will be a key process supporting this initiative. In terms of specific recommendations, the scales of monitoring in co-management should be aligned with those over which fishers perceive the resource, and the participatory development of indicator systems may provide a more intuitive and acceptable scientific approach to monitoring and setting management targets.

\section{ACKNOWLEDGEMENTS}

We gratefully acknowledge the cooperation and time of Seychellois trap fishers, especially Peter Tirant and Hetson Oreddy. Vincent Savy, Gregory Berke, Maria Cedras and Christine Henriette assisted with fieldwork. Simon Jennings collected the 1994 UVC data. Selina Stead, Tim Gray, Tim McClanahan and Tony Hawkins provided advice and comments. The manuscript was substantially improved by comments from Nicholas Polunin, Ioan Fazey and two anonymous referees. Maps were provided by Calvin Gerry from Seychelles Fishing Authority. Funding was provided by the Western Indian Ocean Marine Science Association MASMA program, the Leverhulme Trust, a NERC/ESRC Ph.D. studentship (T. M. Daw) and a Fisheries Society of the British Isles Ph.D. studentship (N. A. J. Graham).

\section{References}

Adams, W.M., Brockington, D., Dyson, J. \& Vira, B. (2003) Managing tragedies: understanding conflict over common pool resources. Science 302(5652): 1915-1916.

Ames, T. (2007) Putting fishers' knowledge to work: reconstructing the Gulf of Maine cos spawning grounds on the basis of local ecological knowledge. In: Fishers' Knomledge in Fisheries Science and Management, ed. N. Haggan, B. Neis \& I.G. Baird, pp. 353363. Paris, France: UNESCO.

Armitage, D.R., Plummer, R., Berkes, F., Arthur, R.I., Charles, A.T., Davidson-Hunt, I.J., Diduck, A.P., Doubleday, N.C., Johnson, D.S., Marschke, M., McConney, P., Pinkerton, E.W. \& Wollenberg, E.K. (2009) Adaptive co-management for socialecological complexity. Frontiers in Ecology and the Environment 7(2): 95-102.

Balcetis, E. \& Dunning, D. (2007) Cognitive dissonance and the perception of natural environments. Psychological Science 18(10): 917-921. 
Berkes, F. (2006) From community-based resource management to complex systems: the scale issue and marine commons. Ecology and Society 11(1).

Berkes, F., Mahon, R., McConney, P., Pollnac, R. \& Pomeroy, R. (2001) Managing Small-scale Fisheries: Alternative Directions and Methods. Ottawa, Canada: International Development Research Centre.

Bunce, M., Rodwell, L.D., Gibb, R. \& Mee, L. (2007) Shifting baselines in fishers' perceptions of island reef fishery degradation. Ocean and Coastal Management. 51(4): 285-302.

Burnham, K.P. \& Anderson, D.R. (2002) Model Selection and Multimodel Inference: a Practical Information-theoretic Approach. New York, NY, USA: Springer-Verlag.

Carpenter, S.R. \& Brock, W.A. (2006) Rising variance: a leading indicator or ecological transition. Ecology Letters 9: 311318.

Charles, A.T. (1998) Living with uncertainty in fisheries: analytical methods, management priorities and the Canadian groundfishery experience. Fisheries Research 37: 37-50.

Crona, B. \& Bodin, O. (2006) What you know is who you know? Communication patterns among resource users as a prerequisite for co-management. Ecology and Society 11(2).

Davis, A. \& Wagner, J.R. (2003) Who knows? On the importance of identifying 'Experts' when researching local ecological knowledge. Human Ecology 31(3): 463-489.

Daw, T.M. (2008) How fishers count: engaging fishers' knowledge in fisheries science and management. Ph.D. thesis, School of Marine Science and Technology, and School of Geography, Politics and Sociology, Newcastle University, Newcastle upon Tyne, UK [www document]. URL http://www.tinyurl.com/tdaw-thesis

de Mutsert, K., Cowan, J.H., Essington, T.E. \& Hilborn, R. (2008) Reanalyses of Gulf of Mexico fisheries data: landings can be misleading in assessments of fisheries and fisheries ecosystems. Proceedings of the National Academy of Sciences 105(7): 2740 2744.

Dulvy, N.K. \& Polunin, N.V.C. (2004) Using informal knowledge to infer human-induced rarity of a conspicuous reef fish. Animal Conservation 7: 365-374.

Edgar, G.J., Barrett, N.S. \& Morton, A.J. (2004) Biases associated with the use of underwater visual census techniques to quantify the density and size-structure of fish populations. Fournal of Experimental Marine Biology and Ecology 308(2): 269-290.

Eigaard, O.R. (2009) A bottom-up approach to technological development and its management implications in a commercial fishery. ICES Journal of Marine Sciences 66: 916-927.

FAO (2005) Putting into practice the ecosystem approach to fisheries. Report. Food and Agriculture Organization of the United Nations, Rome, Italy: $76 \mathrm{pp}$.

Fazey, I., Fazey, J.A., Salisbury, J.G., Lindenmayer, D.B. \& Dovers, S. (2006) The nature and role of experiential knowledge for environmental conservation. Environmental Conservation 33(1): 110.

Finlayson, A.C. (1994) Fishing for Truth: A Sociological Analysis of Northern Cod Stock Assessments from 1977 to 1990. St Johns, Newfoundland, Canada: ISER.

Folke, C., Colding, J. \& Berkes, F. (2003) Chapter 14. Synthesis. In: Navigating Social-Ecological Systems: Building Resilience for Complexity and Change, ed. F. Berkes, J. Colding \& C. Folke, pp. 1-29. Cambridge, UK: Cambridge University Press.

Froese, R. \& Pauly, D., eds (2006) FishBase [www document]. URL http://www.fishbase.org
Gerhardinger, L.C., Marenzi, R.C., Bertoncini, A.A, Medeiros, R.P. \& Hostim-Silva, M. (2006) Local ecological knolwedge on the goliath grouper Epinephelus itajara (Teliostei: Serranidae) in southern Brazil. Neotropical Ichthyology 4(4): 441-450.

Graham, N.A.J., Wilson, S.K., Jennings, S., Polunin, N.V.C., Bijoux, J.P. \& Robinson, J. (2006) Dynamic fragility of oceanic coral reef ecosystems. Proceedings of the National Academy of Sciences of the United States of America 103(22): 8425-8429.

Graham, N.A.J., Wilson, S.K., Jennings, S., Polunin, N.V.C., Bijoux, J.P. \& Daw, T.M. (2007) Lag effects in the impacts of mass coral bleaching on coral reef fish, fisheries and ecosystems. Conservation Biology 21(5): 1291-1300.

Gray, T., Hatchard, J., Daw, T.M. \& Stead, S.M. (2008) New cod war of words: 'cod is God' versus 'sod the cod': two opposed discourses on the North Sea Cod Recovery Programme. Fisheries Research 93(1-2): 1-7.

Haggan, N. \& Neis, B. (2007) The changing face of fisheries science and management. In: Fishers' Knomledge in Fisheries Science and Management, ed. N. Haggan, B. Neis \& I.G. Baird, pp. 421-432. Paris, France: UNESCO.

Haggan, N., Neis, B. \& Baird, I.G. (2007) Fishers' Knowledge in Fisheries Science and Management. Paris, France: UNESCO: 437 pp.

Hall-Arber, M. (2003) It's pretty fishy ... Maritime Studies 2(1): 42-44.

Harmon-Jones, E. \& Harmon-Jones, C. (2007) Cognitive dissonance theory after 50 years of development. Zeitschrift für Sozialpsychologie 38: 7-16.

Hilborn, R. \& Walters, C.J. (1992) Quantitative Fisheries Stock Assessment. Choice, Dynamics and Uncertainty. New York, NY, USA: Chapman and Hall: 570 pp.

Hoefnagel, E., Burnett, A. \& Wilson, D.C. (2006) Chapter 4. The knowledge base of co-management. In: The Knomledge Base for Fisheries Management, ed. L. Motos \& D.C. Wilson, pp. 85-108. Amsterdam, the Netherlands: Elsevier.

Hoffmann-Riem, H. \& Wynne, B. (2002) In risk assessment, one has to admit ignorance: explaining there are things we can't know could improve public confidence in science. Nature 416: 123123.

Holm, P. (2003) Crossing the border: on the relationship between science and fishermen's knowledge in a resource management context. Maritime Studies 2: 5-33.

Hsieh, C.H., Reiss, C.S. Hunter, J.R. Beddington, J.R., May, R.M. \& Sugihara, G. (2006) Fishing elevates variability in the abundance of exploited species. Nature 443(7113): 859-862.

Jennings, S., Grandcourt, E.M. \& Polunin, N.V.C. (1995) The effects of fishing on the diversity, biomass and trophic structure of Seychelles' reef fish communities. Coral Reefs 14: 225-235.

Jennings, S., Kaiser, M.J. \& Reynolds, J.D. (2001) Marine Fisheries Ecology. Malden, UK: Blackwell: 417 pp.

Jentoft, S., McCay, B.J. \& Wilson, D.C. (1998) Social theory and fisheries co-management. Marine Policy 22(4-5): 423-436.

Johannes, R.E. (1998) The case for data-less marine resource management: examples from tropical nearshore finfisheries. Trends in Ecology and Evolution 13(6): 243-245.

Johannes, R.E. \& Neis, B. (2007) The value of anecdote. In Fishers' Knomledge in Fisheries Science and Management, ed. N. Haggan, B. Neis \& I.G. Baird, pp. 41-58. Paris, France: UNESCO.

Kollmuss, A. \& Agyeman, J. (2002) Mind the gap: why do people act environmentally and what are the barriers to pro-environmental behavior? Environmental Education Research 8(3): 239-260. 
Lavides, M.N., Polunin, N.V.C., Stead, S.M., Tabaranza, D.G., Comeros, M.T. \& Dongallo, J.R. (2009) Finfish disappearances around Bohol, Philippines inferred from traditional ecological knowledge. Environmental Conservation 36: 235-244.

Letourneur, Y., Kulbicki, M. \& Labrosse, P. (1998) Length-weight relationships of fishes from coral reefs and lagoons of New Caledonia: an update. Naga ICLARM Quarterly 21: 39-46.

Lunn, K.E. \& Dearden, P. (2006) Monitoring small-scale marine fisheries: an example from Thailand's Ko Chang archipelago. Fisheries Research 77: 60-70.

Matlin, M.W. (2004) Cognition. Hoboken, NY, USA: Wiley.

Maurstad, A. (2000) Trapped in biology: an interdisciplinary attempt to integrate fish harvesters' knowledge into Norwegian fisheries management. In: Finding Our Sea Legs: Linking Fishery People and Their Knomledge with Science and Managment, ed. B. Neis \& L. Felt, pp. 135-152. St Johns, Newfoundland, Canada: ISER.

McClanahan, T.R., Hicks, C.C. \& Darling, E.S. (2008) Malthusian overfishing and efforts to overcome it on Kenyan coral reefs. Ecological Applications 18(6): 1516-1529.

Mees, C.C. (1990) Seychelles artisanal catch assessment survey: notes for implementation. Report. Seychelles Fishing Authority, Victoria, Seychelles: $39 \mathrm{pp}$.

Miller, C.A. (2000) The dynamics of framing environmental values and policy: four models of societal processes. Environmental Values 9: 211-233

Moller, H., Berkes, F. Lyver, P.O.B. \& Kislalioglu, M. (2004) Combining science and traditional ecological knowledge: monitoring populations for co-management. Ecology and Society 9(3): 2.

Murray, G.., Neis, B., Palmer, C. \& Schneider, D. (2008) Mapping cod: fisheries science, fish harvesters' ecological knowledge and cod migrations in the northern Gulf of St Lawrence. Human Ecology 36(4): 581-598.

Neis, B. (1997) Fishers' ecologcal knowledge and stock assessment in Newfoundland. In: How deep is the Ocean? Historical Essays on Canada's Atlantic Fishery, ed. J.E. Candow \& C. Corbin, pp. 243260. Sydney, Nova Scotia, Canada: University College of Cape Breton Press.

Neis, B., Schneider, D.C., Felt, L., Haedrich, R.L., Fischer, J. \& Hutchings, J.A. (1999) Fisheries assessment: what can be learned from interviewing resource users? Canadian Fournal of Fisheries and Aquatic Sciences 56(10): 1949-1963.

O'Donnell, K.P., Pajaro, M.G. \& Vincent, A.C.J. (2010) How does the accuracy of fisher knowledge affect seahorse conservation status? Animal Conservation 13: 526-533.

Oostenbrugge, J.A.E., Densen, W.L.T. \& Machiels, M.A.M. (2001) Risk aversion in allocating fishing effort in a highly uncertain coastal fishery for pelagic fish, Moluccas, Indonesia. Canadian Fournal of Fisheries and Aquatic Sciences 58(8): 16831691.
Ostrom, E., Burger, J., Field, C.B., Norgaard, R.B. \& Policansky, D. (1999) Revisiting the commons: local lessons, global challenges. Science 284: 278-282.

Papworth, S.K., Rist, J., Coad, L. \& Milner-Gulland, E.J. (2009) Evidence for shifting baseline syndrome in conservation. Conservation Letters 2(2): 93-100.

Pet-Soede, C., Van Densen, W.L.T., Hiddink, J.G., Kuyl, S. \& Machiels, M.A.M. (2001) Can fishermen allocate their fishing effort in space and time on the basis of their catch rates? An example from Spermonde Archipelago, SW Sulawesi, Indonesia. Fisheries Management and Ecology 8(1): 15-36.

Quirijns, F.J., Poos, J.J. \& Rijnsdorp, A.D. (2008) Standardizing commercial cpue data in monitoring stock dynamics: accounting for targeting behaviour in mixed fisheries. Fisheries Research 89: $1-8$.

Robinson, J., Isidore, M.,. Marguerite, M.A., Öhman, M.C. \& Payet, R.J. (2004) Spatial and temporal distribution of reef fish spawning aggregations in the Seychelles: an interview-based survey of artisanal fishers. Western Indian Ocean Journal of Marine Science 3: 63-69.

Rochet, M-J., Prigent, M., Bertrand, J.A., Carpentier, A., Coppin, F., Delpech, J-P., Fontenelle, G., Foucher, E., Mahé, K., Rostiaux, E. \& Trenkel, V.M. (2008) Ecosystem trends: evidence for agreement between fishers' perceptions and scientific information. ICES Fournal of Marine Science 65: 1057-1068.

Saenz-Arroyo, A., Roberts, C.M., Torre, J., Carino-Olvera, M. \& Enriquez-Andrade, R.R. (2005) Rapidly shifting environmental baselines among fishers of the Gulf of California. Proceedings of the Royal Society B-Biological Sciences 272(1575): 1957-1962.

Schwarz, N. (1999) Self-reports: how questions shape the answers. American Psychologist 54(2): 93-105.

Tversky, A. \& Kahnema, D. (1973) Availability: a heuristic for judging frequency and probability. Cognitive Psychology 5: 207232.

Tversky, A. \& Kahneman, D. (1974) Judgment under uncertainty: heuristics and biases. Science 185: 1124-1131.

van Densen, W.L.T. (2001) On the perception of time trends in resource outcome. Its importance in fisheries co-management, agriculture and whaling. Ph.D. thesis. Twente University, Enschede, the Netherlands: 299 pp.

Walmsley, S., Howard, C. \& Medley, P. (2005) Participatory Fisheries Stock Assessment (ParFish): Guidelines. London, UK: MRAG: $166 \mathrm{pp}$.

Verweij, M.C., van Densen, W.L.T. \& Mol, A.J.P. (2010) The tower of Babel: different perceptions and controversies on change and status of North Sea fish stocks in multi-stakeholder settings. Marine Policy 34(3): 522-533.

Zuur, A.F., Ieno, E.N. \& Smith, G.M. (2007) Analysing Ecological Data. New York, NY, USA: Springer-Verlag: $672 \mathrm{pp}$. 